\title{
Ataxia Telangiectasia Diagnosed on Newborn Screening-Case Cohort of 5 Years' Experience
}

\author{
Amarilla B. Mandola ${ }^{1,2}$, Brenda Reid ${ }^{1,2}$, Raga Sirror ${ }^{3}$, Rae Brager ${ }^{4}$, Peter Dent ${ }^{4}$, \\ Pranesh Chakroborty ${ }^{5}$, Dennis E. Bulman ${ }^{5}$ and Chaim M. Roifman ${ }^{1,2 *}$ \\ ${ }^{1}$ Division of Immunology and Allergy, Department of Paediatrics, The Hospital for Sick Children and the University of Toronto, \\ Toronto, ON, Canada, ${ }^{2}$ The Canadian Centre for Primary Immunodeficiency and the Jeffrey Modell Research Laboratory for \\ the Diagnosis of Primary Immunodeficiency, the Hospital for Sick Children, Toronto, ON, Canada, ${ }^{3}$ Paediatric \\ Allergy/Immunology, Thunder Bay Regional Health Sciences Center, North Ontario School of Medicine, Thunder Bay, ON, \\ Canada, ${ }^{4}$ Division of Rheumatology, Immunology, and Allergy, Department of Paediatrics, McMaster Children's Hospital, \\ McMaster University, Hamilton, ON, Canada, ${ }^{5}$ Department of Pediatrics, CHEO Research Institute and Newborn Screening \\ Ontario, University of Ottawa, Ottawa, ON, Canada
}

\section{OPEN ACCESS}

Edited by:

Lennart Hammarström

Karolinska Institutet (KI), Sweden

Reviewed by:

Anders Fasth,

University of Gothenburg, Sweden

Kohsuke Imai

Tokyo Medical and Dental University, Japan

*Correspondence:

Chaim M. Roifman

chaim.roifman@sickkids.ca

Specialty section: This article was submitted to

Primary Immunodeficiencies,

a section of the journal

Frontiers in Immunology

Received: 30 August 2019 Accepted: 29 November 2019 Published: 20 December 2019

Citation:

Mandola $A B$, Reid $B$, Sirror $R$, Brager R, Dent $P$, Chakroborty $P$, Bulman DE and Roifman CM (2019) Ataxia Telangiectasia Diagnosed on Newborn Screening-Case Cohort of 5

Years' Experience.

Front. Immunol. 10:2940.

doi: 10.3389/fimmu.2019.02940
Ataxia telangiectasia (AT) is a genetic condition caused by mutations involving ATM (Ataxia Telangiectasia Mutated). This gene is responsible for the expression of a DNA double stranded break repair kinase, the ATM protein kinase. The syndrome encompasses combined immunodeficiency and various degrees of neurological abnormalities and increased risk of malignancy. Typically, patients present early in life with delay in neurological milestones, but very infrequently, with life threatening infections typical of a profound $T$ cell deficiency. It would therefore be unexpected to identify this condition immediately after birth using $T$ cell receptor excision circle (TREC)-based newborn screening (NBS) for SCID. We sought to evaluate the frequency of AT detected by NBS, and to assess immunity as well as the genetic aberrations associated with this early presentation. Here, we describe the clinical, laboratory, and genetic features of patients diagnosed with AT through the Ontario NBS program for SCID, and followed in our center since its inception in 2013. Four patients were diagnosed with AT as a result of low TRECs on NBS. In each case, whole exome sequencing was diagnostic. All of our patients had compound heterozygous mutations involving the FRAP-ATM-TRRAP (FAT) domain of the ATM gene, which appears critical for kinase activity and is highly sensitive to mutagenesis. Our patients presented with profound lymphopenia involving both $\mathrm{B}$ and T cells. The ratio of naïve/memory CD45+RA/RO T cells population was variable. T cell repertoire showed decreased $T$ cell diversity. Two out of four patients had decreased specific antibody response to vaccination and hypogammaglobulinemia requiring IVIG replacement. In two patients, profound decreased responses to phytohemagglutinin stimulation was observed. In the other two patients, the initial robust response declined with time. In summary, the rate of detection of AT through NBS had been surprisingly high at our center. One case was identified per year, while the total rate for SCID has been five new cases per year. This early detection may allow for better prospective evaluation of AT shortly after birth, and may assist in formulating early and more effective interventions both for the neurological as well as the immune abnormalities in this syndrome. 


\section{INTRODUCTION}

The protein kinase Ataxia Telangiectasia Mutated (ATM) is a high molecular weight PI3K-family kinase involved in the phosphorylation of multiple proteins, including in key cellular functions such as gene transcription and expression, response to oxidative stress, and energy metabolism. Together, ATM acts as a temporal gate keeper for proper cell division and appropriate repair (1-3).

Ataxia telangiectasia (AT) is an autosomal recessive syndrome encompassing progressive neuronal degeneration, ocular and cutaneous telangiectases, variable immunodeficiency, and cancer susceptibility. The ESID diagnostic criteria for AT includes ataxia and at least two of the following features: (a) oculocutaneous telangiectasia, (b) elevated alpha-fetoprotein (AFP), (c) typical AT karyotype (translocation of chromosomes 7; 14), (d) cerebellum hypoplasia on MRI (4). The criteria do not include neurological abnormalities, likely because of its inconsistency, great variability, and due to challenges in obtaining data from pediatric examination.

By controlling cell cycle and DNA repair, ATM plays an important role in the development and function of both the cellular and humoral immune system. The development of appropriate $\mathrm{T}$ cell receptor (TCR) repertoire is dependent on the repair of $\mathrm{V}(\mathrm{D}) \mathrm{J}$ recombination-induced breaks by the nonhomologous end-joining (NHEJ) pathway, which is promoted by $\operatorname{ATM}(5,6)$. Proper class-switch recombination is facilitated by ATM, through the correction of breaks by a Ku-dependent endjoining pathway, as well as preventing aberrant translocations due to double strand breaks and propagating the $\mathrm{Ku}$-independent alternative NHEJ (A-NHEJ) pathway $(5,7,8)$.

Diagnosis of AT patients may be delayed due to the wide variability in clinical phenotype; the syndrome is frequently confused with cerebral palsy and the immunological evaluation overlooked or misdiagnosed as Hyper-immunoglobulin M syndrome (9-12).

Review of the literature reveals that the immunological presentation of AT is highly variable; IgA concentrations are low in more than $50 \%$ of cases, IgM levels are elevated in up to $60 \%$ of cases, but low IgG is infrequent (occurring in $10-18 \%$ of cases). Numbers of T cells, in particular CD4+ cells, may decline over time in $30-75 \%$ of cases. However, profound lymphopenia in neonates was not well-recognized prior to the introduction of NBS (13-15), and the AT cases that have since been identified by TREC/KREC in infants (16-18) are likely an underestimate of the true number of patients affected. The complete absence of ATM enzyme activity is much more likely to result in clinical and/or immunological features of immunodeficiency compared to those who retain residual activity (19).

We describe here four patients with AT identified by the NBS system in Ontario, Canada.

\section{METHODS}

\section{Patients}

This study conformed to the Declaration of Helsinki and all local ethical requirements. Information on presentation, complications, laboratory parameters, management, and outcomes were compiled both prospectively and retrospectively using parent interview and medical chart review. All laboratory results were analyzed with reference to age-related normal ranges. Written informed consent was obtained from the parents or guardians of the participant for the publication of this study.

\section{TREC Determination From Guthrie Blood Spots}

Methodology for the assessment of TREC levels by qPCR was performed as previously described (20).

\section{Lymphocyte Proliferation}

Lymphocyte proliferative responses were assayed to mitogens including phytohemagglutinin (PHA) and anti-CD3. All assays were performed in triplicate and were compared with simultaneously stimulated normal controls, as previously described (21).

\section{Chromosome Breakage Analysis and G-Band Evaluation}

For chromosome spontaneous breakage frequency evaluation, fifty metaphases were examined by solid stain analysis. One hundred metaphase cells from a 3-day PHA-stimulated lymphocyte culture were examined by G-band analysis. Chromosome rearrangements involving regions $7 \mathrm{p} 14,7 \mathrm{q} 34$, and $14 \mathrm{q} 11.2$ were evaluated in metaphase cells.

\section{Whole Exome Sequencing and Variant Calling}

DNA from blood was submitted to The Center for Applied Genomics (TCAG), Toronto, Canada for exome library preparation and sequencing. DNA was quantified by Qubit DNA HS assay (Life Technologies, Carlsbad, CA) and $100 \mathrm{ng}$ of input DNA was used for library preparation using the Ion AmpliSeq Exome Kit (Life Technologies) according to the manufacturer's recommendations. The Ampliseq Exome library was immobilized on Ion $\mathrm{PI}^{\mathrm{TM}}$ Ion Sphere ${ }^{\mathrm{TM}}$ particles using the Ion PI Template OT2 200 Kit v3. Sequencing was performed with the Ion PI Sequencing 200 Kit v3 and Ion PI Chip v2 in the Ion Proton ${ }^{\mathrm{TM}}$ semiconductor sequencing system following the manufacturer's recommendation. Alignment and variant calling were performed using Torrent Suite (v4.0) on the Ion Proton Server, using the Ion Proton AmpliSeq germline low stringency setting and the hg19 reference genome. The variants were annotated using an in-house annotation pipeline (22) based on Annovar (November 2014 version) (23) and RefSeq gene models (downloaded from UCSC 01 August 2015).

\section{Sanger Sequencing}

Patients' genomic DNA was extracted from peripheral blood lymphocytes using the Geneaid Genomic DNA Mini Kit. Genomic DNA was amplified by PCR with specific primers designed upstream and downstream of the ATM gene. Sequencing was done using GenomeLab Dye Terminator Cycle Sequencing (DTCS) Quick Start Kit (Beckman 


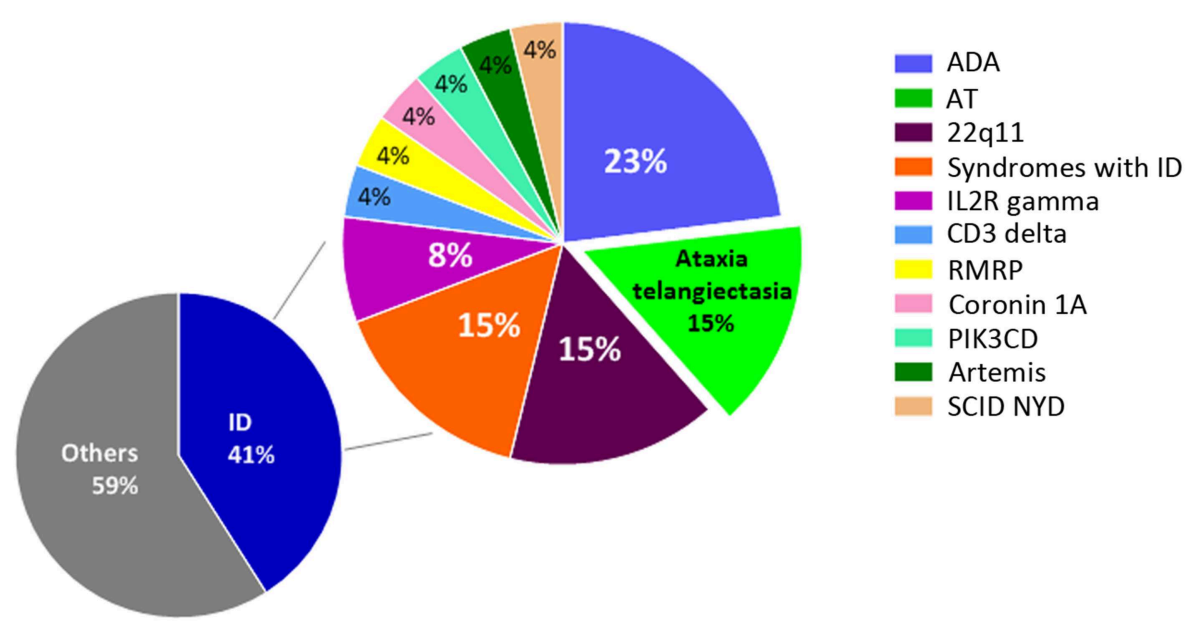

FIGURE 1 | Positive NBS results for SCID at the Hospital for Sick Children from 2013 to 2018 . A total of 63 infants were NBS positive for SCID at our center. Of the 26 cases with confirmed immunodeficiency, 23\% were diagnosed with adenosine deaminase deficiency (ADA), 15\% with ataxia telangiectasia (AT), 15\% with syndromes involving immunodeficiency (ID), 8\% with IL2R gamma deficiency, and 4\% each with deficiencies of CD3 delta, RMRP, coronin 1A, PIK3CD, Artemis, and SCID not yet defined (NYD). The remaining 37 cases were associated with maternal immunosuppression, cardiac post-thymectomy, prematurity, and lymphopenia NYD.

Coulter) and analyzed on CEQ 8000 Genetic Analysis System (Beckman Coulter).

\section{RESULTS}

NBS for Severe Combined Immunodeficiency (SCID) was first introduced in Ontario, Canada, in 2013, and has since been expanded to the Maritime provinces of New Brunswick, Nova Scotia, and Prince Edward Island in 2016. This lifesaving test has yet to be introduced in other jurisdictions of Canada. In Ontario, where there are $\sim 140,000$ births/year, an unexpectedly high number of patients with AT were diagnosed at our center. The Hospital for Sick Children, Toronto, Ontario, is a quaternary hospital with a catchment area of 10 million people. Over the past 5 years, 63 infants at our center were screened positive for SCID on NBS for various reasons (Figure 1). At this point we can conclude that primary immunodeficiencies are more common than estimated in the past, and recent reports suggest that around $1 \%$ of the global population may be affected $(4,24-26)$. The prevalence of AT is estimated to be between 1 in 40,000 and 1 in 100,000 live births, though in certain populations the frequency of mutations are different due to founder effects $(14,27)$.

\section{Patients}

\section{Patient 1}

Patient 1 is the second-born child of a non-consanguineous union with parents of Eastern European origins, with unremarkable family history except for diabetes in a paternal uncle (Figure 2A). His first physical examination at 3 weeks of age was unremarkable, with normal head circumference (30th percentile). At age 12 months, he developed a wobbly gait with mild hypotonia and at 18 months he had oculomotor apraxia, excessive drooling indicative of oro-motor apraxia, and appendicular hypotonia. He had slower baseline gait than expected for age, and truncal ataxia was prominent when walking. Delayed motor development was also observed. His brain MRI was normal. Lymphocyte immunophenotyping revealed reduced numbers of CD19+ $\mathrm{B}$ cells, CD3+, CD4+, and CD8+ T cells, which further declined at 8 months of age (Table 1). The number of CD4+ naïve T cells were diminished, suggesting ineffective thymic production or egress of these cells (Table 2). His T cell repertoire showed decreased diversity, while lymphocyte proliferation responses to PHA were preserved. His humoral evaluation at that time showed normal age referenced immunoglobulin levels, however, the patient's family decided against vaccination, and thus specific antibody titers were not assessed. His AFP level was slightly above normal.

\section{Patient 2}

Patient 2 is the third child born to a non-consanguineous family of English extraction, with a family history of breast cancer in the maternal grandmother and paternal aunt. In addition, the paternal grandmother was diagnosed with cervical cancer and a paternal uncle with a bone tumor (Figure 2B). His first physical examination at age 4 weeks was remarkable for mild axial hypotonia which continued to progress to wobbly gait, stagger, ataxia and mild diffuse hypotonia which were detected at 10 months. The patient's initial immune evaluation as a newborn revealed lymphopenia including reduced numbers of $\mathrm{CD} 19+\mathrm{B}$ cells, CD3+, CD4+, and CD8 $+\mathrm{T}$ cells (Table 1). A repeat evaluation at age 8 months showed progressive lymphopenia with a reduction in $\mathrm{CD} 4+$ naïve $\mathrm{T}$ cells as well as reduced $\mathrm{T}$ cell repertoire diversity (Table 2). Lymphocyte responses to PHA were decreased. His immunoglobulin levels at both 8 and 18 months of age were normal, with sustained specific antibody titres to diphtheria and tetanus. 
A

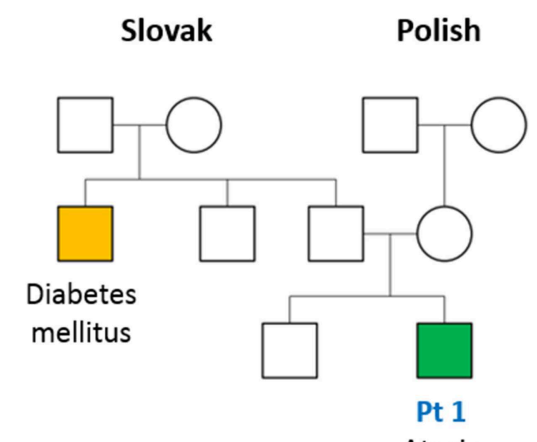

Ataxia

telangiectasia

C

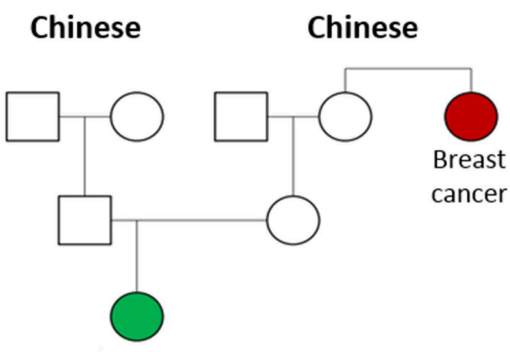

Pt 3

Ataxia

telangiectasia
B

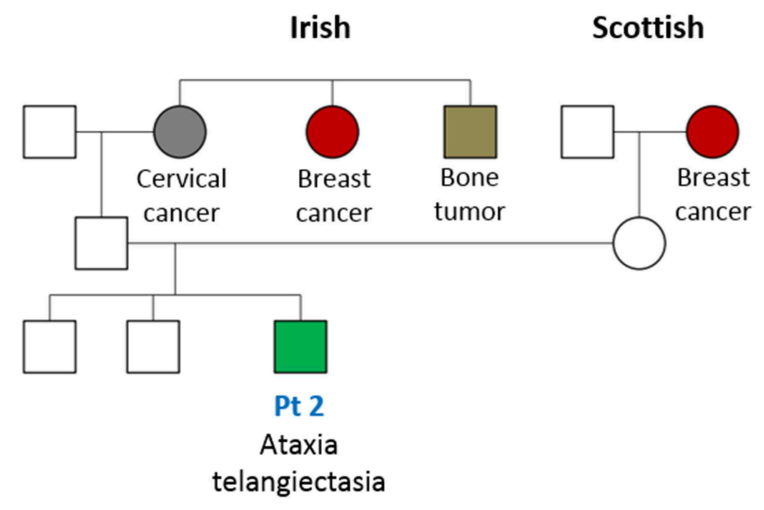

D

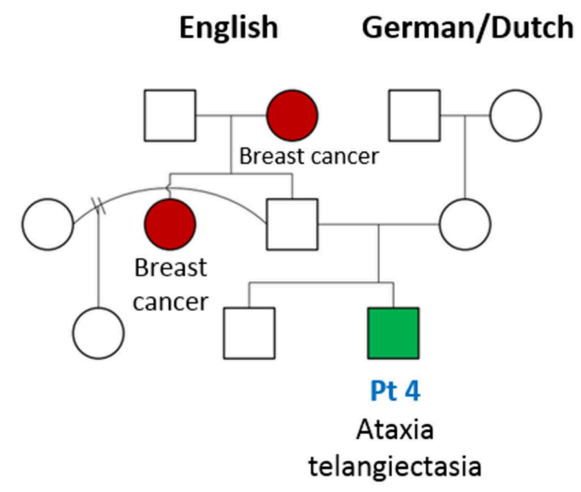

FIGURE 2 | Pedigree of patients with AT diagnosed on newborn screen for SCID. Family tree of patients (Pt) 1-4 (A-D, respectively) in this case series are shown. An increased frequency of cancer, especially breast cancer, in female family members is noted.

TABLE 1 | Initial immune evaluation at SCID retrieval.

\begin{tabular}{|c|c|c|c|c|c|}
\hline & Pt 1 & Pt 2 & Pt 3 & Pt 4 & Reference range \\
\hline Neutrophil count & 2.6 & 0.55 & 2.21 & 2.91 & $1-9.5 \times 10^{9} \mathrm{cells} / \mu \mathrm{L}$ \\
\hline Eosinophil count & 0.8 & 0.25 & 0.22 & 0.83 & $0.07-1 \times 10^{9} \mathrm{cells} / \mu \mathrm{L}$ \\
\hline Thrombocyte count & 440 & 323 & 547 & 737 & $150-400 \times 10^{9} \mathrm{cells} / \mu \mathrm{L}$ \\
\hline CD3+ & 888 & 780 & 1142 & 664 & 2,300-6,500 cells/ $/ \mathrm{L}$ \\
\hline $\mathrm{CD} 3+/ \mathrm{CD} 4+$ & 633 & 262 & 349 & 421 & 1,500-5,000 cells/ $\mu \mathrm{L}$ \\
\hline CD3+/CD8+ & 233 & 485 & 759 & 228 & 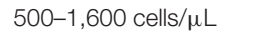 \\
\hline NK & 528 & 531 & 440 & 258 & $100-1,300$ cells $/ \mu \mathrm{L}$ \\
\hline PHA (Stimulation Index, SI) & 563 & 416 & 151 & 158 & $>450 \mathrm{SI}$ \\
\hline CD3 Mitogen Stimulation & ND & Normal & 7.2 (C:216) & 9.3 (C:255) & \\
\hline
\end{tabular}

C, control; ND, not determined; bold text indicates values that fall outside of the reference range.

\section{Patient 3}

Patient 3 is the first-born child of a non-consanguineous family of Chinese ethnicity, with a family history of breast cancer in the maternal aunt (Figure 2C). Her first physical examination at age 3 weeks revealed axial hypotonia and her head circumference was below the 5th percentile for age, where it remained thereafter. At 12 months of age, profound hypotonia, nystagmus, unbalanced gait, and feeding problems became apparent, and 
TABLE 2 | Immunological evaluation at age 8 months.

\begin{tabular}{|c|c|c|c|c|c|}
\hline & Pt 1 & Pt 2 & Pt 3 & Pt 4 & Reference range \\
\hline White blood cell count & 6.18 & 5.13 & 3.2 & 3.4 & $5-20 \times 10^{9} \mathrm{cells} / \mu \mathrm{L}$ \\
\hline Neutrophil count & 2.8 & 2.9 & 1.09 & 0.8 & $1-9.5 \times 10^{9} \mathrm{cells} / \mu \mathrm{L}$ \\
\hline Lymphocyte count & 1.7 & 1.27 & 0.34 & 1.5 & $2-17 \times 10^{9} \mathrm{cells} / \mu \mathrm{L}$ \\
\hline Eosinophil count & 0.38 & 0.1 & 0.26 & 0.4 & $0.07-1 \times 10^{9} \mathrm{cells} / \mu \mathrm{L}$ \\
\hline Thrombocyte count & 510 & 394 & 466 & 614 & $150-400 \times 10^{9} \mathrm{cells} / \mu \mathrm{L}$ \\
\hline CD3+ & 645 & 677 & 664 & 823 & 2,300-6,500 cells/ $\mu \mathrm{L}$ \\
\hline CD19+ & 118 & 186 & 116 & 201 & 600-3,000 cells/ $\mu \mathrm{L}$ \\
\hline $\mathrm{CD} 3+/ \mathrm{CD} 4+$ & 466 & 370 & 441 & 550 & 1,500-5,000 cells/ $\mu \mathrm{L}$ \\
\hline CD3+/CD8+ & 109 & 242 & 182 & 235 & 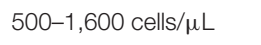 \\
\hline NK & 685 & 531 & 581 & 547 & $100-1,300$ cells $/ \mu \mathrm{L}$ \\
\hline $\mathrm{CD} 4+/ \mathrm{CD} 45+\mathrm{RA}+$ & 10 (C:44) & $16.4(\mathrm{C}: 34)$ & $11(C: 33)$ & 14 (C:23) & \\
\hline $\mathrm{CD} 4+/ \mathrm{CD} 45+\mathrm{RO}+$ & 38 (C:17) & 39.8 (C:19) & $10(\mathrm{C}: 12)$ & 20 (C:9) & \\
\hline $\lg G$ & 2.8 & 5.5 & $<1.1$ & $<1.1$ & $1.1-7.0 \mathrm{~g} / \mathrm{L}$ \\
\hline $\lg M$ & 0.7 & 0.2 & 1 & 1.2 & $0.1-0.7 \mathrm{~g} / \mathrm{L}$ \\
\hline $\lg A$ & 0.1 & 0.1 & $<0.1$ & $<0.1$ & $0.1-3 \mathrm{~g} / \mathrm{L}$ \\
\hline Anti-pneumococcal Ab & Not vaccinated & 11 & on IVIG & on IVIG & \\
\hline Anti-tetanus toxoid Ab & Not vaccinated & 2.86 & 0.16 & 0.03 (5 mo) & $>0.1$ \\
\hline Diphtheria toxoid Ab & Not vaccinated & 3 & on IVIG & on IVIG & $>0.01$ \\
\hline AFP & 23 & 56 & 152 & 70 & $<21 \mathrm{ng} / \mathrm{mL}$ \\
\hline
\end{tabular}

Ab, antibody; C, control; IVIG, intravenous immunoglobulin; mo, months; bold text indicates values that fall outside of the reference range.

at 18 months she was found to have additional neurological features including dysarthria, dysmetria, nystagmus, ataxia, and oculo-oro-motor apraxia. The patient's initial immune evaluation while a newborn demonstrated reduced numbers of CD19+ B cells, CD3+, CD4+, and CD8+ T cells which further declined when assessed at 8 months of age (Table 1). The number of CD4+ naïve $\mathrm{T}$ cells were reduced and she had a limited $\mathrm{T}$ cell repertoire (Table 2). Her lymphocyte proliferation responses to PHA were remarkably depressed. Humoral evaluation at age 8 months showed severe hypogammaglobulinemia including low $\operatorname{IgG}(\operatorname{IgG}<1.1)$, low IgA level $(\operatorname{Ig} A<0.1)$, elevated $\operatorname{IgM}(\operatorname{IgM}$ $=1$ ), and undetectable antibody responses to vaccines, requiring immunoglobulin replacement. Her AFP at age 8 months was greatly elevated (152).

\section{Patient 4}

Patient 4 is the second-born child of a non-consanguineous family of European origin, with a family history of breast cancer in a paternal aunt and grandmother (Figure 2D). His initial physical examination at age 3 weeks was unremarkable, but at 12 months he developed a wobbly gait with mild hypotonia, and at 18 months he had ataxia with unstable stance and gait, drooling, and oro-motor apraxia. The patient's initial immune evaluation while a newborn revealed reduced numbers of CD19+ $\mathrm{B}$ cells, CD3+, CD4+, and CD8+ T cells (Table 1), with further decline observed at 8 months (Table 2). His $\mathrm{T}$ cell repertoire was limited, and lymphocyte proliferation responses to PHA were very low. He had severe hypogammaglobulinemia including low IgG $(\operatorname{IgG}<1.1)$ and low IgA level $(<0.1)$, elevated IgM
(1.2), and undetectable titers to childhood vaccines, requiring immunoglobulin replacement. His AFP at age 8 months was very elevated $(70 \mathrm{ng} / \mathrm{mL})$.

\section{Genetic Work Up}

Following the finding of a positive NBS for SCID, and in the context of broader presenting features, we performed G-band analysis that, in each of these patients, demonstrated significant chromosome re-arrangements involving $\mathrm{T}$ cell receptor gamma, beta, and alpha/delta gene loci at chromosome locations 7p14, $7 \mathrm{q} 35$, and 14q11.2, and elevated frequency of spontaneous breakage. Whole exome sequencing (WES) revealed compound heterozygous mutations in the ATM gene in each patient (Table 3). The mutations were confirmed by Sanger sequencing and segregation studies showed that parents were heterozygous carriers of those mutations.

In Patient 1, WES revealed a c. $331+1 \mathrm{G}>\mathrm{A}$ mutation predicting p.Ser111Asn amino acid change affecting a splice donor site, and possibly disrupting the HEAT (Huntingin, elongation factor 3, protein phosphatase 2A, TOR1) domain. The second mutation, c.6095G $>$ A, predicting p.Arg2032Lys amino acid change involves the FAT (Focal adhesion kinase targeting) domain. In Patient 2, two pathogenic variants, c.170G $>A$ (p.Trp57*) and c.6997dupA (p.Thr2333Asnfs*40), involving both the HEAT and FAT domains were identified. Genetic evaluation of Patient 3 revealed two mutations within the FAT domain, c.6679C>T, (p.Arg2227Cys; pathogenic), c.7090-1G>A (p.Lys2363Arg; novel). Similarly, in Patient 4, the mutations c.5228C > T (p.Thr1743Ile; likely pathogenic) and c.6908dupA 
TABLE 3 | SCID NBS TREC levels and genetic evaluation results.

\begin{tabular}{|c|c|c|c|c|}
\hline & Pt 1 & Pt 2 & Pt 3 & Pt 4 \\
\hline $\begin{array}{l}\text { TRECs (copies/ } \\
3 \mu \mathrm{L} \text { DNA) } \\
\text { (cut-off > } 75 \\
\text { copies/3 } \mu \mathrm{L} \text { ) }\end{array}$ & 22 & 23 & 26 & 41 \\
\hline $\begin{array}{l}\text { WES/Sanger } \\
\text { sequencing }\end{array}$ & $\begin{array}{l}\text { c. } 331+1 G>A ; \\
\text { c. } 6095 G>A\end{array}$ & $\begin{array}{l}\text { c. } 170 G>A \\
\text { c. } 6997 \text { dupA }\end{array}$ & $\begin{array}{l}\text { c. } 6679 \mathrm{C}>\mathrm{T} \\
\text { c. } 7090-1 \mathrm{G}>\mathrm{A}\end{array}$ & $\begin{array}{l}\text { c. } 5228 \mathrm{C}>\mathrm{T} \\
\text { c.6908dupA }\end{array}$ \\
\hline Affected region & $\begin{array}{l}\text { FAT domain } \\
\text { HEAT repeats }\end{array}$ & $\begin{array}{l}\text { FAT domain } \\
\text { HEAT repeats }\end{array}$ & $\begin{array}{l}\text { FAT domain } \\
\text { FAT domain }\end{array}$ & $\begin{array}{l}\text { FAT domain } \\
\text { FAT domain }\end{array}$ \\
\hline $\begin{array}{l}\text { G-band analysis } \\
\text { assay }\end{array}$ & Positive & Positive & Positive & Positive \\
\hline
\end{tabular}

Bold text indicates values that fall outside of the reference range.

(p.Glu2304Glyfs*69; pathogenic) were both localized to the FAT domain.

\section{DISCUSSION}

The implementation of TREC-based SCID NBS in Ontario, Canada, has enabled the early detection and diagnosis of SCID that would otherwise be missed or delayed until the onset of life-threatening infections. Unfortunately, it appears that many cases of significant $\mathrm{T}$ cell deficiencies cannot be detected by this methodology. Surprisingly, some non-SCID conditions have been rarely detected by NBS (28). AT has not been typically regarded as having a SCID-like clinical course or fate.

In our cohort, we describe four patients with AT who all presented with low TRECs on SCID NBS. The initial approach to patients with an abnormal SCID NBS in Canada is described in Biggs et al. (29). All had profound, sustained B and T cell lymphopenia, which is consistent with low thymic output. Our patients had low naïve CD4+/CD45+ RA+ populations compared to age appropriate controls. Three patients presented with decreased lymphocyte proliferation responses. Two out of the four patients showed early onset humoral immunodeficiency and were started on immunoglobulin replacement therapy.

Patients with AT are rarely diagnosed in the first year of life, largely because their typical neurological manifestations are noted at a later age. Many are incorrectly diagnosed with cerebral palsy. Early detection at the newborn age leads to the correct diagnosis and might aid in early interventions. However, this may pose an ethical conundrum since some jurisdictions, such as the Netherlands, do not allow the screening and reporting of diseases for which there is no cure. In Ontario, the finding of a positive SCID newborn screen, regardless of underlying cause, triggers urgent follow-up evaluation in accordance with our Ministry of Health-approved algorithm for assessment and treatment of such cases (30).

Each of our patients carry compound heterozygous mutations in the ATM gene, one of which is a pathogenic variant localized to the FAT domain. As expected, patients' pedigrees also show an increased frequency of cancer, especially breast cancer in female family members.
The detection of AT by NBS was first reported in 2012 in Swedish newborns (6) and subsequently in other jurisdictions where NBS for SCID has been implemented $(31,32)$. We have shown here that AT, if detected early by TREC-based NBS, has a more profound immunological and neurological phenotype, and this intuitively might predict a more severe disease course.

Early genetic diagnosis of AT enables very early patient centered and individualized interventions, including physiotherapy, neurological support, proper immunological evaluation, and infection prevention before onset of complications (PJP prophylaxis and IVIG before the development of bronchiectasis). Moreover, it may also aid in further understanding possible genotype-phenotype correlations.

\section{CONCLUSION}

We have demonstrated that AT can be detected shortly after birth by NBS for SCID. AT should be considered in cases with NBS positivity because of its relatively high frequency, as shown in our cohort (15\%). This early detection allows for early referral to specialized centers for comprehensive evaluation and guidance. It enables the provision of individualized intervention for patients as well as genetic counseling for the family members, especially mothers, who, as carriers, have an increased risk of developing breast cancer and other malignancies. Furthermore, the early detection of immune abnormalities allows for appropriate treatment to prevent or minimize the otherwise complicated disease course that AT patients may suffer.

\section{DATA AVAILABILITY STATEMENT}

The raw data supporting the conclusions of this study will be made available upon request.

\section{ETHICS STATEMENT}

The studies involving human participants were reviewed and approved by the Research Ethics Board, Hospital for Sick Children. Written informed consent to participate in this study was provided by the participants' legal guardian/next of kin.

\section{AUTHOR CONTRIBUTIONS}

$\mathrm{CR}$ and $\mathrm{AM}$ conceptualized and designed the study and wrote the initial draft of the manuscript. BR, RS, RB, and PD were involved in the clinical care of the patients. DB and PC evaluated NBS TRECs. All authors contributed to manuscript revision, read, and approved the submitted manuscript.

\section{FUNDING}

This work was supported by Immunodeficiency Canada's Distinguished Professorship in Immunology (CR), the Program for Immunogenomics and the Canadian Center for Primary Immunodeficiency (CR), and the Jeffrey Modell Foundation and Immunodeficiency Canada (CR). 


\section{REFERENCES}

1. McKinnon PJ. ATM and the molecular pathogenesis of ataxia telangiectasia. Ann Rev Pathol. (2012) 7:303-21. doi: 10.1146/annurev-pathol-011811-132509

2. Ambrose M, Gatti RA. Pathogenesis of ataxia-telangiectasia: the next generation of ATM functions. Blood. (2013) 121:4036-45. doi: 10.1182/blood-2012-09-456897

3. Schon K, van Os NJH, Oscroft N, Baxendale H, ScoffingsD, Ray J, et al. Genotype, extrapyramidal features, and severity of variant ataxiatelangiectasia. Ann Neurol. (2019) 85:170-80. doi: 10.1002/ana.25394

4. Seidel MG, Kindle G, Gathman B, Quinti I, Buckland M, van Montfrans J, et al. The European Society for Immunodeficiencies (ESID) registry working definitions for the clinical diagnosis of inborn errors of immunity. J Aller Clin Immun. (2019) 7:1763-70. doi: 10.1016/j.jaip.2019.02.004

5. Bredemeyer AL, Sharma GG, Huang CY, Helmink BA, Walker LM, Khor KC, et al. ATM stabilizes DNA double-strand-break complexes during V(D)J recombination. Nature. (2006) 442:466-70. doi: 10.1038/nature 04866

6. Borte S, von Döbeln U, Fasth A, Wang N, Janzi M, Winiarski J, et al. Neonatal screening for severe primary immunodeficiency diseases using high-throughput triplex real-time PCR. Blood. (2012) 119:2552-5. doi: 10.1182/blood-2011-08-371021

7. Lumsden JM, McCarty T, Petiniot LK, Shen R, Barlow C, Wynn TA, et al. Immunoglobulin class switch recombination is impaired in atm-deficient mice. J Exp Med. (2004) 200:1111-21. doi: 10.1084/jem.20041074

8. Reina-San-Martin B, Chen HT, Nussenzweig A, Nussenzweig MC. ATM is required for efficient recombination between immunoglobulin switch regions. J Exp Med. (2004) 200:1103-10. doi: 10.1084/jem.20041162

9. van Os NJH, Jansen AFM, van Deuren M, Haraldsson A, van Driel NTM, Etzioni A, et al. Ataxia-telangiectasia: immunodeficiency and survival. Clin Immunol. (2018) 178:45-55. doi: 10.1016/j.clim.2017.01.009

10. Azarsiz E, Karaca NE, Gunaydin NC, Gulez N, Ozturk C, Aksu G, et al. Do elevated serum IgM levels have to be included in probable diagnosis criteria of patients with Ataxia-telangiectasia? Int J Immunopathol Pharmacol. (2014) 27:421-7. doi: 10.1177/039463201402700312

11. Aghamohammadi A, Imai K, Moazzami K, Abolhassani H, Tabatabaeiyan $\mathrm{M}$, Parvaneh $\mathrm{N}$, et al. Ataxia-telangiectasia in a patient presenting with hyper-immunoglobulin $\mathrm{M}$ syndrome. J Investig Allergol Clin Immunol. (2010) 20:442-5.

12. Noordzij JG, Wulffraat NM, Haraldsson A, Meyts I, van't Veer LJ, Hogervorst $\mathrm{FB}$, et al. Ataxia-telangiectasia patients presenting with hyper-IgM syndrome. Arch Dis Child. (2009) 94:448-9. doi: 10.1136/adc.2008.149351

13. Minto H, Mensah KA, Reynolds PR, Meffre E, Rubtsova K, Gelfand EW. A novel ATM mutation associated with elevated atypical lymphocyte populations, hyper-IgM, and cutaneous granulomas. Clin Immunol. (2019) 200:55-63. doi: 10.1016/j.clim.2019.01.002

14. Rothblum-Oviatt C, Wright J, Lefton-Greif M, McGrath-Morrow SA, Crawford TO, Lederman HM. Ataxia telangiectasia: a review. Orphanet J Rare Dis. (2016) 11:1-21. doi: 10.1186/s13023-016-0543-7

15. Nowak-Wegrzyn A, Crawford TO, Winkelstein JA, Carson KA, Lederman HM. Immunodeficiency and infections in ataxia-telangiectasia. J Pediatr. (2004) 144:505-11. doi: 10.1016/j.jpeds.2003.12.046

16. Kamae C, Nakagawa N, Sato H, Honma K, Mitsuiki N, Ohara O, et al. Common variable immunodeficiency classification by quantifying T-cell receptor and immunoglobulin $\kappa$-deleting recombination excision circles. J Allergy Clin Immunol. (2013) 131:1437-1440.e5. doi: 10.1016/j.jaci.2012.10.059

17. de Felipe B, Olbrich P, Lucenas JM, Delgado-Pecellin C, Pavon-Delgado A, Marquez J, et al. Prospective neonatal screening for severe T- and Blymphocyte deficiencies in Seville. Pediatr Allergy Immunol. (2016) 27:70-7. doi: 10.1111/pai.12501

18. Nourizadeh M, Shakerian L, Borte S, Fazlollahi M, Badalzadeh M, Houshmand M, et al. Newborn screening using TREC/KREC assay for severe
T and B cell lymphopenia in Iran. Scand J Immunol. (2018) 2018:e12699. doi: $10.1111 /$ sji.12699

19. Driessen GJ, Ijspeert H, Weemaes CM, Haraldsson Á, Trip M, Warris A, et al. Antibody deficiency in patients with ataxia telangiectasia is caused by disturbed b- and t-cell homeostasis and reduced immune repertoire diversity. J Allergy Clin Immunol. (2013) 131:1367-75.e9. doi: 10.1016/j.jaci.2013.01.053

20. Suresh S, Dadi H, Reid B, Vong L, Bulman DE, Roifman CM. Time-dependent decline of T-cell receptor excision circle levels in ZAP-70 deficiency. J Allergy Clin Immunol Pract. (2019). doi: 10.1016/j.jaip.2019.08.018. [Epub ahead of print].

21. Sharfe N, Nahum A, Newell A, Dadi H, Ngan B, Pereira SL, et al. Fatal combined immunodeficiency associated with heterozygous mutation in STAT1. J Aller Clin Immunol. (2014) 133:807-17. doi: $10.1016 /$ j.jaci.2013.09.032

22. Stavropoulos DJ, Merico D, Jobling R, Bowdin S, Monfared N, Thiruvahindrapuram B, et al. Whole genome sequencing expands diagnostic utility and improves clinical management in paediatric medicine. NPJ Genom Med. (2016) 1:15012. doi: 10.1038/npigenmed.2015.12

23. Wang K, Li M, Hakonarson H. ANNOVAR: functional annotation of genetic variants from high-throughput sequencing data. Nucleic Acids Res. (2010) 38:e164. doi: 10.1093/nar/gkq603

24. Boyle JM, Buckley RH. Population prevalence of diagnosed primary immunodeficiency diseases in the United States. J Clini Immunol. (2007) 27:497-502. doi: 10.1007/s10875-007-9103-1

25. Modell V, Orange JS, Quinn J, Modell F. Global report on primary immunodeficiencies: 2018 update from the jeffrey modell centers network on disease classification, regional trends, treatment modalities, and physician reported outcomes. Immunol Res. (2018) 66:367-80. doi: 10.1007/s12026-018-8996-5

26. Bousfiha AA, Jeddane L, Ailal F, Benhsaien I, Mahlaoui N, Casanova JL, et al. Primary immunodeficiency diseases worldwide: more common than generally thought. J Clin Immunol. (2013) 33:1-7. doi: 10.1007/s10875-012-9751-7

27. Teive HA, Moro A, Moscovich M, Arruda WO, Munhoz RP, Raskin $\mathrm{S}$, et al. Ataxia-telangiectasia - a historical review and a proposal for a new designation: ATM syndrome. J Neurol Sci. (2015) 355:3-6. doi: 10.1016/j.jns.2015.05.022

28. Kwan A, Puck JM. History and current status of newborn screening for severe combined immunodeficiency. Semin Perinatol. (2015) 39:194-205. doi: 10.1053/j.semperi.2015.03.004

29. Biggs CM, Haddad E, Issekutz TB, Roifman CM, Turvey SE. Newborn screening for severe combined immunodeficiency: a primer for clinicians. CMAJ. (2017) 189:E1551-7. doi: 10.1503/cmaj.170561

30. Reid B, Ovadia A, Dinur Schejter Y. Managing newborn screening for SCID in a referral centre. LymphoSign J. (2017) 4:77-9. doi: 10.14785/lymphosign-2017-0005

31. Mallott J, Kwan A, Church J, Gonzalez-Espinosa D, Lorey F, Tang LF, et al. Newborn screening for SCID identifies patients with ataxia telangiectasia. $J$ Clin Immunol. (2013) 33:540-9. doi: 10.1007/s10875-012-9846-1

32. Cousin MA, Smith MJ, Sigafoos AN, Jin JJ, Murphree MI, Boczek NJ, et al. Utility of DNA, RNA, protein, and functional approaches to solve cryptic immunodeficiencies. J Clin Immunol. (2018) 38:307-19. doi: 10.1007/s10875-018-0499-6

Conflict of Interest: The authors declare that the research was conducted in the absence of any commercial or financial relationships that could be construed as a potential conflict of interest.

Copyright (c) 2019 Mandola, Reid, Sirror, Brager, Dent, Chakroborty, Bulman and Roifman. This is an open-access article distributed under the terms of the Creative Commons Attribution License (CC BY). The use, distribution or reproduction in other forums is permitted, provided the original author(s) and the copyright owner(s) are credited and that the original publication in this journal is cited, in accordance with accepted academic practice. No use, distribution or reproduction is permitted which does not comply with these terms. 